\title{
它迎只A
}

Article

\section{Physiological Responses of Youth Players During Wheelchair Basketball Games}

\author{
Ryan T. Conners ${ }^{1 *}$, Jeremy M. Elliott ${ }^{1}$, David L. Kyle ${ }^{1}$, Stacy Solomon ${ }^{2}$, \& Paul N. \\ Whitehead ${ }^{1}$ \\ Received: $16^{\text {th }}$ June 2019; Accepted: $12^{\text {th }}$ March 2020; Published: $7^{\text {th }}$ July 2020
}

\begin{abstract}
The purpose of this study was to document physiological responses that result from participation in youth wheelchair basketball (WCB) games. Each participant ( 4 males, 2 females, mean age $=15.2 \mathrm{y}, \mathrm{SD}=1.8 \mathrm{y}$ ) completed a peak aerobic capacity upper-body cycle ergometer test until fatigue. Additionally, each participant competed in two regular season youth WCB games while wearing a Polar Pro Team System heart rate (HR) monitor. During competition, average HR, peak heart rate (HRpeak), playing intensity, total distance covered, training load score, and caloric expenditure were recorded. Results from the study indicated a $\mathrm{HR}$ mean $=140.8 \mathrm{~b} \cdot \mathrm{min}^{-1}, \mathrm{SD}=19.8 \mathrm{~b} \cdot \mathrm{min}^{-1}$, HRpeak mean $=188.9 \mathrm{~b} \cdot \mathrm{min}^{-1}, \mathrm{SD}=$ $15.8 \mathrm{~b} \cdot \mathrm{min}^{-1}$, and mean $=83.3 \%, \mathrm{SD}=13.7 \%$ level of exercise intensity from participation in the two games. Additionally, participation in WCB games revealed that players traversed mean $=909.4$ meters, $\mathrm{SD}=230.4$ meters, achieved a training load score mean $=120.3, \mathrm{SD}=65.2$, and expended mean $=718.2$ calories, $\mathrm{SD}=184.5$ calories, across the two games. In conclusion, participation by adolescents in a WCB game meets the physiological demands needed to achieve health-related fitness benefits established by both the American College of Sports Medicine and the Centers for Disease Control and Prevention.
\end{abstract}

Keywords: Adapted sport; aerobic capacity; caloric expenditure; heart rate monitoring system; adolescents

\section{Introduction}

Four million or $5.4 \%$ of the adolescent population in the United States, are estimated to have a disability (Kraus, 2017; U.S. Census Bureau QuickFacts, 2016). People with disabilities often experience reduced activity levels, which could further symptoms of their disability (Dunlop et al., 2015; Maher, Williams, Olds, \& Lane, 2007). Exercise in the adolescent without disabilities population has been associated with reduced fatigue and secondary illnesses as well as improved mood status, self-esteem (Calfas \& Taylor, 1994; Landers \& Petruzzello, 1994), and academic performance (Castelli, Hillman, Buck, \& Erwin, 2007; Ortega, Ruiz, Castillo, \& Sjöström, 2008). Furthermore, exercise has been shown to reduce the probability of suffering a myocardial infraction by $25 \%$ to $33 \%$ in individuals who expend $\geq 2000$ kcal per week (Abel, Platen, Rojas Vega, Schneider, \& Strüder, 2008; Paffenbarger, Hyde, Wing, \& Hsieh, 1986). Thus, it is important for both adolescents with and without disabilities to be physically active. However, finding means of increasing participation in adequate exercise is crucial for adolescents with disabilities to perform, due to their increased likelihood of decreased muscle mass and low-exercise lifestyles compared to adolescents without disabilities (Abel et al., 2008). 
With respect to the level of health-producing exercise in youth, the American College of Sports Medicine (ACSM) has set guidelines for the range of exertion where exercise is beneficial. According to these recommendations, exercise at $55-90 \%$ of heart rate peak $\left(\mathrm{HR}_{\text {peak }}\right)$ or $40-85 \%$ of maximum aerobic capacity $\left(\mathrm{VO}_{2 \mathrm{max}}\right)$ is sufficient to provide fitness benefits (American College of Sports Medicine, 2018). However, there are additional challenges that adolescents with disabilities face in meeting these ideal exercise goals. One of the biggest barriers to exercise in adolescents with disabilities is an overall lack of time (Kang, Zhu, Ragan, \& Frogley, 2007). For youth under the age of 21, making exercise a priority can be difficult to balance along with school responsibilities, extracurricular activities, and other obligations (Amsterdam, Knoppers, \& Jongmans, 2015). Furthermore, it has been shown that adults with disabilities require additional transportation time, setup time, or assistance in adaptive sports, adding a great burden for those looking to participate and making it difficult to meet established physical activity guidelines (Rimmer, Riley, Wang, Rauworth, \& Jurkowski, 2004). Similar encumbrances are likely for adolescents with disabilities as well (Moody et al., 2004).

To increase opportunities for physical activity in adolescents with disabilities, adapted sports teams and leagues have become more prevalent (Yanci, Iturricastillo, \& Granados, 2014). In particular, wheelchair basketball (WCB) has become an increasingly popular option for physical activity among adolescents with disabilities (Yanci et al., 2014). Participation in WCB incorporates a high amount of upper body exercise and provides a team sport environment for individuals with special exercise considerations. Previous research has shown that upper body exercise results in greater increase in heart rate, blood pressure, and pulmonary ventilation compared to lower-body exercise (Miles et al., 1984; Sawka, Miles, Petrofsky, Wilde, \& Glaser, 1982). However, more investigation is needed to determine these effects in the adolescent population. This observational study was designed to expand upon published research performed in a popular adapted sport, while focusing specifically on the adolescent population (Croft, Dybrus, Lenton, \& Goosey-Tolfrey, 2010; Roy, Menear, Schmid, Hunter, \& Malone, 2006; Yanci et al., 2014).

Given the increase in adolescent participation in WCB, research is needed to help determine the overall demands that are placed on youth players involved in the sport. Past research with WCB has predominantly included adult participants, who often perform at the Paralympic or elite level. For example, a study utilizing 13 female players from the German National Wheelchair Basketball team showed high cardiovascular stress during a game, with an average heart rate of $151 \mathrm{~b} \cdot \mathrm{min}^{-1}$ during game play (Schmid et al., 1998). However, caution must be taken in applying results for adults to adolescent athletes, due to the potential differences in motivational levels (Brasile \& Hedrick, 1991). Elite athletes with sport-specific conditioning would also be expected to exhibit different physiological responses than youth players with less physical conditioning. If the physiological demands that are present in youth athletes as they have been reported for adults, the minimum threshold of achieving physical activity guidelines will be easily met, and research can help quantify that.

Given the increasing number of adolescents with disabilities (22.4\%) in the United States (U.S. Census Bureau QuickFacts, 2018), identifying effective means of exercise is vital. Inadequate space, inaccessibility to equipment, or lack of equipment can often lead to time limitations being imposed during participation in exercise for adolescents with disabilities, whereas WCB may afford adequate exposure to activity for those with special exercise considerations. By determining the level of intensity that youth players exert while playing, WCB can be identified as a safe, effective, and positive health intervention for adolescent with disabilities. Therefore, the purpose of our study was to measure the physiological responses in adolescents with spina bifida and cerebral palsy while participating in a WCB 
game. We hypothesized that youth WCB athletes would attain sufficient levels of exercise intensity to meet exercise guidelines outlined by the ACSM (American College of Sports Medicine, 2018) and by the Center for Disease Control (Piercy et al., 2018).

\section{Materials and Methods}

\section{Participants}

The University of Alabama in Huntsville Institutional Review Board (Approval Number FR201754) approved the study prior to active recruitment of participants. Participants also received clearance from their personal physician and provided written informed parental consent/child assent before participation. Study participants included six (4 males, 2 female) youth WCB players (mean $=15.2 \mathrm{y}, \mathrm{SD}=1.8 \mathrm{y}$, mean $=159 \mathrm{~cm}, \mathrm{SD}=72 \mathrm{~cm}$, mean $=$ $74.7 \mathrm{~kg}, \mathrm{SD}=35.4 \mathrm{~kg}$ ) from the southeastern United States youth WCB players. Each youth athlete has permanent physical impairments associated with either cerebral palsy or spina bifida (Table 1). The WCB classification system (see Table 1) involves categorizing individuals as either junior one ( $\mathrm{J} 1$ ) players (International Wheelchair Basketball Federation classes 1.0, 1.5, 2.0, or 2.5 point value) or junior 2 (J2) players (International Wheelchair Basketball Federation classes 3.0, 3.5, 4.0, and 4.5 point value), based on their physical capacity to perform fundamental basketball movements (e.g., shooting, dribbling, pushing the wheelchair) (“Junior Classification," 2019).

J1 players traditionally display limited trunk control, forward stability, and limited vertical stability when they are in their sports chair ("Junior Classification", 2019), whereas J2 players are characterized by active control of their trunks and increased movement in both the forward and vertical planes ("Junior Classification", 2019). A team with all male players can only have a total of 8 classification points on the court during game play but a team with at least one female athlete playing can have a total of 9 (Junior Classification, 2019).

\section{Procedures}

To assess cardiovascular fitness, an arm ergometer test was used to determine $\mathrm{VO}_{\text {2peak }}$

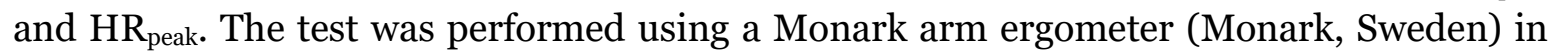
conjunction with a Parvo, Metabolic metabolic cart (Parvo, Metabolic metabolic cart, Sandy, Utah, USA, 2015). The $\mathrm{VO}_{\text {peak }}$ Monark arm ergometer protocol utilized in this study, was previously used by wheelchair athletes in a study by Roy et al. (2006). Prior to testing, a twostage calibration was performed. The Parvo, Metabolic metabolic cart was powered on 30 minutes prior to calibration (Macfarlane and $\mathrm{Wu}, 2013$ ). The metabolic cart was calibrated according to manufacturer's guidelines, which consisted of a room air auto-calibration (with a two-point gas calibration protocol from a single gas tank), and a flow meter calibration performed before each testing session (Crouter, Clowers, \& Bassett, 2006). A branching protocol was used for the arm ergometer test that included a 2-minute warm-up at o watts (W) (Hunter, Weinsier, McCarthy, Enette, \& Newcomer, 2001; Roy et al., 2006). After the 2-minute warm-up, the protocol continued in 1-minute stages. If the HR after the warm-up was lower than $110 \mathrm{~b} \cdot \mathrm{min}^{-1}$, the first increment in workload was $20 \mathrm{~W}$; conversely, if $\mathrm{HR}$ after the warm-up was greater than $110 \mathrm{~b} \cdot \mathrm{min}^{-1}$, the first increment was $10 \mathrm{~W}$. Subsequent increments in workload of $10 \mathrm{~W}$ occurred in 1-min intervals.

During the test, participants were asked to maintain a minimum cycling frequency of $60 \mathrm{rev} \cdot \mathrm{min}^{-1}$ and a maximum value of $70 \mathrm{rev} \cdot \mathrm{min}^{-1}$. The test was continued until voluntary exhaustion or cycling frequency dropped below $60 \mathrm{rev} \cdot \mathrm{min}^{-1}$. Three criteria, adopted from Roy et al. (2006), were used to evaluate achievement of $\mathrm{VO}_{\text {2peak: }} \mathrm{HR}$ no lower than $10 \mathrm{~b} \cdot \mathrm{min}^{-}$ ${ }^{1}$ below age-predicted $\mathrm{HR}_{\text {peak }}$ (220 - age in years); a respiratory exchange ratio of at least 1.1; 
and attaining a $\mathrm{VO}_{2}$ plateau, defined as an increase in $\mathrm{Vo}_{2}$ of less than $0.4 \mathrm{ml} \cdot \mathrm{kg}^{-1} \cdot \mathrm{min}^{-1}$ in the final stage of the test. During testing, HR was measured via telemetry using a Polar HR monitor (Polar, Kempele, Finland) that was strapped around the participant's chest and transmitted data to the metabolic testing system.

Cardiovascular and physiological responses during competition were measured while participants played in two regularly scheduled WCB games against Junior WCB teams from the same conference. Each WCB game consisted of two 20-minute halves. The WCB games took place one week after the cardiovascular fitness test had been completed. Therefore, there was adequate rest prior to competition and no cardiovascular detraining. Each participant was equipped with a Polar Team Pro HR monitor that recorded HR in 5-second intervals throughout the games. The average $\mathrm{HR}$ and $\mathrm{HR}_{\text {peak }}$ during the games were calculated for each participant. Relative exercise intensity during individual game play was calculated by dividing the average $H R$ achieved during each game played by the $H_{\text {peak }}$ obtained in the arm ergometer test.

\section{Data analysis}

Statistical analyses were performed using the IBM SPSS Statistics for Windows, Version 24.O. Armonk, NY: IBM Corp.. Paired sample $t$ tests were used to compare HR average, $\mathrm{HR}_{\text {peak, }}$ level of intensity, total distance, training load score, and caloric expenditure between the two WCB games. Statistical significance was established at $p \leq .05$.

\section{Results}

No injuries were reported during the study. Individual participant descriptive statistics are reported in Table 1. The average VO2peak on the cycle ergometer for the participants was mean $=22.0 \mathrm{ml} \cdot \mathrm{kg}^{-1} \cdot \mathrm{min}^{-1}, \mathrm{SD}=6.0 \mathrm{ml} \cdot \mathrm{kg}^{-1} \cdot \mathrm{min}^{-1}$ and HRpeak was mean $=171.5 \mathrm{~b} \cdot \mathrm{min}-$ ${ }^{1}, \mathrm{SD}=260 \mathrm{~b} \cdot \mathrm{min}^{-1}$. All of the WCB participants achieved the necessary criteria for a valid $\mathrm{VO}_{2 p e a k}$ test. Additionally, the two basketball games had an average duration of 80.5 minutes (Game $1=82$ minutes \& Game 2 = 79 minutes).

Table 1. Individual participant descriptive statistics

\begin{tabular}{|c|c|c|c|c|c|c|c|}
\hline Participant & $\begin{array}{l}\text { Age } \\
(\text { yrs })\end{array}$ & $\begin{array}{l}\text { Height } \\
(\mathrm{cm})\end{array}$ & $\begin{array}{l}\text { Weight } \\
\text { (kg) }\end{array}$ & Disability & $\begin{array}{l}\text { NWBA } \\
\text { Classification }\end{array}$ & 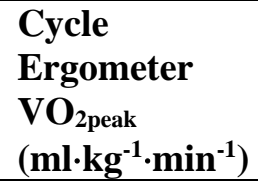 & $\begin{array}{l}\text { Cycle } \\
\text { Ergometer } \\
\text { HR }_{\text {peak }} \\
(\text { b·min } \\
\end{array}$ \\
\hline 1 & 14 & 161 & 136 & S.B. & $\mathrm{J} 1$ & 15.2 & 178 \\
\hline 2 & 13 & 152 & 43.6 & S.B. & $\mathrm{J} 1$ & 29.3 & 193 \\
\hline 3 & 16 & 161 & 54.7 & C.P. & $\mathrm{J} 1$ & 29.3 & 167 \\
\hline 4 & 16 & 172 & 98.6 & S.B. & $\mathrm{J} 1$ & 17.2 & 179 \\
\hline 5 & 14 & 153 & 57 & S.B. & $\mathrm{J} 2$ & 21.0 & 122 \\
\hline 6 & 18 & 158 & 58.2 & S.B. & $\mathrm{J} 1$ & 20.2 & 190 \\
\hline
\end{tabular}

S.B. = Spina bifida; C.P. = Cerebral palsy; J1 = Junior 1; J2 = Junior 2. NWBA = National Wheelchair Basketball Association.

Individual game values for all variables are presented in Table 2 and Table 3 . The average HR between the two wheelchair games was not significantly different $(t=.097, p=$ .926). However, $\mathrm{HR}_{\text {peak }}$ achieved during the first game was significantly higher compared to the second game $(t=5.455, p=.003)$. The level of intensity $(t=0.143, p=.892)$ and total distance covered $(t=1.540, p=.184)$ during the two WCB games were not significantly different. Although the level of intensity and distance covered were not significantly different between the two games, there was a significant difference in training load score $(t=2.569$, $p=.050)$ and caloric expenditure $(t=5.630, p=.002)$ between the first and second game. 
Table 2. Wheelchair basketball performance characteristics in Game 1

\begin{tabular}{lllllll}
\hline Participant & $\begin{array}{l}\text { HR } \\
\text { Avg. }\end{array}$ & HR $_{\text {Peak }}$ & $\begin{array}{l}\text { Playing } \\
\text { Intensity }\end{array}$ & $\begin{array}{l}\text { Total } \\
\text { Distance }\end{array}$ & $\begin{array}{l}\text { Training } \\
\text { Load }\end{array}$ & $\begin{array}{l}\text { Caloric } \\
\text { Expend. }\end{array}$ \\
\hline 1 & 153 & 202 & 86.0 & 1452.0 & 97.0 & 1189.0 \\
2 & 151 & 191 & 78.0 & 1173.0 & 208.0 & 764.0 \\
3 & 149 & 203 & 89.1 & 1193.0 & 206.0 & 942.0 \\
4 & 117 & 179 & 65.5 & 727.0 & 48.0 & 706.0 \\
5 & 125 & 176 & 90.2 & 1182.0 & 92.0 & 625.0 \\
6 & 151 & 220 & 79.7 & 500.0 & 172.0 & 824.0 \\
\hline
\end{tabular}

Game 1 was a loss and the final score was 36 to $55 . \mathrm{HR}$ Avg = bpm; HReak = bpm; Playing Intensity = Avg. $\mathrm{HR} / \mathrm{VO}_{2} \mathrm{HR}_{\text {Peak}}$; Total Distance $=\mathrm{m}$; Training Load $=$ Score based on the intensity and duration of the training session performed; Caloric Expend = kcal.

Table 3. Wheelchair basketball performance characteristics in Game 2

\begin{tabular}{lllllll}
\hline Participant & $\begin{array}{l}\text { HR } \\
\text { Avg. }\end{array}$ & HR $_{\text {Peak }}$ & $\begin{array}{l}\text { Playing } \\
\text { Intensity }\end{array}$ & $\begin{array}{l}\text { Total } \\
\text { Distance }\end{array}$ & $\begin{array}{l}\text { Training } \\
\text { Load }\end{array}$ & $\begin{array}{l}\text { Caloric } \\
\text { Expend. }\end{array}$ \\
\hline 1 & 148 & 192 & 83.0 & 620.0 & 64.0 & 823.0 \\
2 & 146 & 177 & 76.5 & 994.0 & 134.0 & 509.0 \\
3 & 151 & 198 & 90.0 & 932.0 & 151.0 & 674.0 \\
4 & 101 & 168 & 56.8 & 334.0 & 14.0 & 370.0 \\
5 & 124 & 163 & 95.2 & 876.0 & 63.0 & 437.0 \\
6 & 173 & 198 & 91.2 & 931.0 & 194.0 & 755.0 \\
\hline
\end{tabular}

Game 2 was a win and the final score was 36 to $12 . \mathrm{HR}$ Avg = bpm; HReak = bpm; Playing Intensity = Avg.

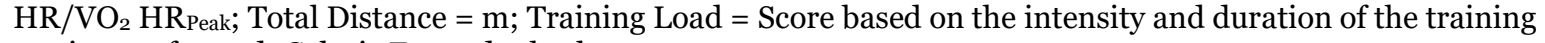
session performed; Caloric Expend = kcal.

\section{Discussion}

The purpose of this study was to measure physiological responses that occur in adolescent with disabilities during participation in a WCB game. A total of two WCB games were observed to determine absolute and relative exercise intensity. Previous studies reporting the physiological demands of wheelchair sports have typically focused on highly competitive adults (Coutts, 1988; Croft et al., 2010; Perez, Rabadan, Pacheco, \& Sampedro, 2007; Roy et al., 2006; Sporner et al., 2009). In contrast, the primary objective of the current investigation was to determine if participation in recreational WCB is an effective mode of health-producing exercise for adolescent with disabilities.

The youth WCB participants in our study achieved a mean $\mathrm{VO}_{2 \text { peak }}$ of $22.0 \mathrm{ml} \cdot \mathrm{kg}^{-1} \cdot \mathrm{min}^{-1}$. This value is nearly identical to a $\mathrm{VO}_{\text {2peak }}$ of $21.0 \mathrm{ml} \cdot \mathrm{kg}^{-1} \cdot \mathrm{min}^{-1}$ reported for adult male WCB athletes with spinal cord injuries (Tordi et al., 2001). Our data are also similar to that of a study performed by Janssen, Dallmeijer, Veeger, and van der Woude (2002), which involved 166 adult WCB athletes from five separate samples that had an average $\mathrm{VO}_{2 \text { peak }}$ of $21.6 \mathrm{ml} \cdot \mathrm{kg}^{-}$ ${ }^{1} \cdot \mathrm{min}^{-1}$. The mean $\mathrm{VO}_{2 \text { peak }}$ in the present study was also similar to the $\mathrm{VO}_{\text {ppeak }}$ Mean $=\mathbf{2 5 . 2}$ $\mathrm{ml} \cdot \mathrm{kg}^{-1} \cdot \mathrm{min}, \mathrm{SD}=5.7 \mathrm{ml} \cdot \mathrm{kg}^{-1} \cdot \mathrm{min}$, which was reported from a maximal effort cardiovascular test in 13 children (who were regular wheelchair users) with osteogenesis imperfecta (Bongers, Rijks, Harsevoort, Takken, \& van Brussel, 2016). The similarity in these values indicate the participants of the current study have a fitness level that is representative of the other WCB participants and of other adolescent wheelchair users.

In the current project, the average HR during the two analyzed WCB games was mean $=141 \mathrm{~b} \cdot \mathrm{min}^{-1}, \mathrm{SD}=20 \mathrm{~b} \cdot \mathrm{min}^{-1}$. The average heart rate increases observed during WCB are higher compared to the average heart rate values $\left(100 \mathrm{~b} \cdot \mathrm{min}^{-1}\right)$ achieved by non-ambulatory young wheelchair users who participated in active video gaming (Rowland \& Rimmer, 2012). Although the results of both studies indicated clinically meaningful increases in heart rate above resting values, the higher average increase seen in the current study indicates that 
WCB participation may provide added cardiovascular benefits compared to other activities for non-ambulatory adolescents.

The average HR of $141 \mathrm{~b} \cdot \mathrm{min}^{-1}$ measured in the current study is within range of values noted from other WCB studies involving adult players (Bloxham, Bell, Bhambhani, \& Steadward, 2001; Coutts, 1988; Perez et al., 2007; Schmid et al., 1998). For instance, findings from Coutts (1988) revealed an exercise HR mean $=148 \mathrm{~b} \cdot \mathrm{min}^{-1}, \mathrm{SD}=6 \mathrm{~b} \cdot \mathrm{min}^{-1}$, in 18 male WCB players. In addition, the cardiovascular demand of youth WCB is also comparable to other sports. Specifically, participants in the present study achieved a higher mean HR when compared to an average HR $124.6 \mathrm{~b} \cdot \mathrm{min}^{-1}$ recorded in six skilled wheelchair tennis players during match play (Roy et al., 2006) of volunteer male WCB participants.

The difference in higher mean HR could be due to the fact that children have higher submaximal HR compared to adults. Furthermore, the higher average HR that were achieved in our study may also be due to differences in the level of playing experience and amount of training performed by the athletes. The skilled wheelchair tennis players had an average of 14.8 years of experience playing their sport and trained an average of 8.67 hours per week. The youth WCB athletes in our study only performed an average of 3.25 hours of training per week and had an average of two years of WCB playing experience.

Furthermore, the preliminary findings of the present study indicate that youth WCB players perform at a level of aerobic intensity similar to those of more experienced adult WCB players and basketball players without disabilities. Montgomery, Pyne and Minahan (2010) recorded a mean HR of mean $=147 \mathrm{~b} \cdot \mathrm{min}^{-1}, \mathrm{SD}=10 \mathrm{~b} \cdot \mathrm{min}^{-1}$ in 11 elite junior basketball players without disabilities while engaged in a five-versus-five scrimmage. This was in agreement with previous findings indicating WCB athletes have similar metabolic demands to adult basketball players without disabilities (Ziv \& Lidor, 2009). Also, the data agreed with previous research findings by Miles, Cox and Bomze (1989), which showed that the cardiovascular responses of WCB are directly related to exercise intensity and independent of the amount of muscle mass utilized.

Heart rate is an often-used as indicator of exercise intensity and aerobic fitness during sport play (Esposito et al., 2004). The mean $\mathrm{HR}_{\text {peak }}$ achieved during game 1 was mean $=195$ $\mathrm{b} \cdot \mathrm{min}^{-1}, \mathrm{SD}=13 \mathrm{~b} \cdot \mathrm{min}^{-1}$ and the mean HRpeak achieved during game 2 was mean $=183$ $\mathrm{b} \cdot \mathrm{min}^{-1}, \mathrm{SD}=10 \mathrm{~b} \cdot \mathrm{min}^{-1}$. It is believed the higher $\mathrm{HR}_{\text {peak }}$ obtained in the first game was due to a more intense game (final score 35 to 66) creating an overall higher level of exercise intensity for the athletes. The $\mathrm{HR}_{\text {peak }}$ findings of the present study are higher when compared to a $\mathrm{HR}_{\text {peak }}$ of mean $=18 \mathrm{o} \mathrm{b} \cdot \mathrm{min}^{-1}, \mathrm{SD}=16 \mathrm{~b} \cdot \mathrm{min}^{-1}$, found in 10 adult male WCB players (mean $=30.5 \mathrm{y}, \mathrm{SD}=7.9 \mathrm{y}$ ) who competed at a regional championship level (Piovezana et al., 2017). The mean $H_{\text {peak }}$ values from games 1 and 2 are also higher compared to the mean $\mathrm{HR}_{\text {peak }}$ values found in other WCB studies, who had an average participant age of 25 to 34 years old and reported values of $\mathrm{HR}_{\text {peak }}$ from 167 to $178 \mathrm{~b} \cdot \mathrm{min}^{-1}$ (Coutts, 1988; Croft et al., 2010; Iturricastillo, Yanci, Granados, \& Goosey-Tolfrey, 2016; Yanci et al., 2014). The difference in $\mathrm{HR}_{\text {peak }}$ in this study could be due to the younger mean age of our participants ( mean $=15 \mathrm{y}, \mathrm{SD}=1.8 \mathrm{y}$ ) compared to the previously mentioned WCB studies (Coutts, 1988; Croft et al., 2010; Iturricastillo, et al, 2016; Yanci et al., 2014). Furthermore, the youth WCB athletes may have lower levels of aerobic conditioning compared to higher-level competitors and, therefore, experience a greater level of aerobic exercise intensity during a game (Bogdanis, Nevill, Boobis, \& Lakomy, 1996).

The level of exercise intensity for youth WCB players with spina bifida and cerebral palsy was also identified by observing player metrics throughout game play. The level of physiological demand was assessed using the Polar Team Pro system. The Polar Team Pro system is a live monitoring, team heart rate system that measures HR, speed, distance 
covered, training load score, and caloric expenditure during physical activity and exercise. The level of intensity of game play was obtained by dividing the average HR achieved during the game by the $\mathrm{HR}_{\text {peak }}$ obtained in the $\mathrm{VO}_{\text {2peak }}$ test. The players maintained an average of 83.2\% of $\mathrm{HR}_{\text {peak }}$ across both games. The results of our study are similar to the findings of a study by Dos Santos et al. (2017), which showed levels of intensity in WCB in the range of 55 to $90 \%$ of $\mathrm{HR}_{\text {peak. }}$ The HR values observed in our study represent an intensity level that meets the ACSM recommendations for obtaining health and fitness benefits. The elevated HR intensity levels show that even entry-level players can benefit from the cardiorespiratory demands of WCB.

\section{Performance metrics}

Utilizing wearable smart sensor devices while playing sports has provided new opportunities for research, especially in wheelchair sports (Montgomery et al., 2010). The use of the Polar Team Pro system, provided performance metrics during two WCB games. Overall, the WCB athletes covered mean $=909.5$ meters, $\mathrm{SD}=300.2$ meters per game. This is considerably lower compared to previous studies in which total distance covered in a WCB game was assessed ( 2,700 - 5,000 meters) (Coutts, 1992; Mason, van der Slikke, Hutchinson, Berger, \& Goosey-Tolfrey, 2018; Sporner et al., 2009). In youth WCB, the games consist of two 20-minute halves, whereas an adult WCB game is four 10-minute quarters. The reduction in distance covered during competition could be due to only using the Polar Team Pro system to assess distance. While performing indoor activities, the global positioning system function of the Polar Team Pro system is not utilized to determine total distance covered. However, all movement data is provided by the inertial measurement unit of the Polar Team Pro system, which consists of acceleration, gyroscope, and magnetometer sensors (Fox, O’Grady, Scanlan, Sargent, \& Stanton, 2019; Peltonen \& Tuulari, 2018). The use of a magnetic reed switch and computer-based system (Rhodes, Mason, Perrat, Smith, \& Goosey-Tolfrey, 2014) could provide a more accurate measure of speed and distance covered. Also, we believe the reduced distance covered could be related to the lack of physical capacity to maintain higher-level performance for the entirety of the game (Rhodes et al., 2015). The WCB athletes in this study were young novice players that do not engage in regular amounts of cardiovascular exercise or resistance training. Consequently, they may not have the aerobic fitness level needed for higher court-based performance (Bernardi et al., 2009).

Training load score was another primary outcome variable in our study and it was calculated based on intensity and duration measures from each training session (Manzi, Iellamo, Impellizzeri, D'Ottavio, \& Castagna, 2009). Training load score helps a coach or parent understand the level of intensity being performed, monitor progress throughout a day or week, and compare levels of exercise intensity between a game and a practice. The training load score is based on heart rates obtained during the activity and is further affected by the participant's age, gender, caloric expenditure, and body mass. During WCB game play, an average training load score of $120.3 \pm 65.2$ was achieved in our study, a value that is representative of an extremely demanding exercise for an athlete's session (Manzi et al., 2009).

In addition to training load score, the estimated caloric expenditure of each WCB player was analyzed. An average caloric expenditure of mean $=718.2 \mathrm{kcal}, \mathrm{SD}=184.5 \mathrm{kcal}$ per game was observed. The overall amount of caloric expenditure is higher compared to the study by Roy et al. (2006), who reported an average caloric expenditure between 327.7 and $402.6 \mathrm{kcal}$ per competitive wheelchair tennis match. The caloric expenditure seen in the current study is also higher than mean $=313.6 \mathrm{kcals} \mathrm{h}^{-1}, \mathrm{SD}=101.14 \mathrm{kcals} \mathrm{h}^{-1}$, which was found in a study by Abel et al. (2008), as the mean amount of energy expenditure of wheelchair tennis, rugby, 
and basketball players from a first and second national German league. The higher level of caloric expenditure seen with WCB could be due to the large competitive demand of the sport and having to perform longer distance sprints (Bloxham et al., 2001). Also, WCB involves a higher work to rest ratio, when compared to wheelchair tennis. Thus, WCB may be more physiologically demanding than wheelchair tennis (Croft et al., 2010).

\section{Limitations and future research}

The primary limitation of this study is the small population that exists for youth WCB players. The size of the available sample, and limited number of players on the roster, provides difficulty in conducting more robust physiological research. Also, the variety of disabilities amongst the team members is a limitation for this study. Ideally, the sample would include a larger sample of athletes with the same type of disability. Additionally, an ideal sample would include a larger population of participants possessing a wide array of disabilities. In addition to sample size and variations of disabilities, the competitive intermittent sport of WCB provides additional limitations. Competition levels, game environment, and the demands of the game can vary greatly from one contest to another (Croft et al., 2010; Perez et al., 2007) and could explain some of the variations observed in distance covered, heart rate, and caloric expenditure between the two contests analyzed in this study.

Although there are limitations to the current study, the findings from this study help shine light onto the physiological demands of youth WCB with spina bifida and cerebral palsy. Future research in this area needs to address the training and practice demands of youth WCB. Studies including players from multiple teams will help establish a broader understanding of aerobic stress that results from playing WCB. Additionally, pre-season and post-season evaluations of WCB athletes could help elucidate any potential training effect from participation in youth WCB. The addition of muscular strength and endurance testing could also be utilized to obtain an overall health-related fitness measure for each player. Future research with other adapted sports beyond WCB, could help identify which sports provide meaningful levels of physical activity for adolescent with disabilities. Finally, this study shows that adolescent with spina bifida and cerebral palsy can meet ACSM guidelines for level of activity by participating in WCB. The addition of testing fundamental movement skills and physical fitness measures could be utilized to obtain overall health related and skill related measures for each player (Klavina, Ostrovska, \& Campa, 2017; Temple, Alston, Elder\& Stuart-Hill, 2019). Furthermore, studies could incorporate measurements to assess youth WCB players quality of life and how it affected by being involved with this particular sport (Feter, Calonego, Cavanhi \& del Vecchio, 2018).

\section{Perspectives}

To our knowledge, this is the first study to evaluate the physiological demands of WCB in a youth population. The results indicate that youth WCB players exhibited similar levels of average $\mathrm{HR}, \mathrm{HR}_{\text {peak }}$, total distance, and caloric expenditure when compared to other wheelchair-based sports and, in some aspects, basketball players without disabilities. The average level of intensity of play throughout two WCB games was $83.2 \%$ of $\mathrm{HR}_{\text {peak }}$. Participation in one wheelchair basketball game contributes to the recommended weekly amount of at least 150 minutes to 300 minutes a week of moderate-intensity aerobic physical activity (American College of Sports Medicine, 2018). Also, the duration of a WCB game (40 minutes) meets the Center of Disease Controls (CDC) guidelines for duration of moderate to intense bouts of exercise (30 to 40 minutes of wheeling oneself or 20 minutes of wheelchair basketball) (Piercy et al.., 2018; Rimmer \& Rowland, 2008; Rimmer et al., 2004). Thus, regardless of skill level, WCB is a viable option for adolescent with disabilities to become 
more physically active. In conclusion, participation in a youth WCB game meets the physiological demands needed to achieve health benefits, as indicated by the ACSM and the CDC. Adolescent with disabilities should be encouraged to participate in WCB as a means for engaging in sport and improving overall health and fitness.

\section{Author affiliations:}

1 Department of Kinesiology, The University of Alabama in Huntsville; *Ryan.Conners@uah.edu, jme0017@uah.edu, David.Kyle@uah.edu,pnwo003@uah.edu

2 B.N. College of Nursing, The University of Alabama in Huntsville; slsoo39@uah.edu

* Correspondence: Ryan.Conners@uah.edu; Tel.: +256-824-5202

Author Contributions: Conceptualization: RC, JE, DK; Methodology: RC, DK, PW; Data Analysis; RC, PW, SS; Write-up: RC, JE, DK, SS, PW; Reviewing: RC, JE, DK, SS, PW

Funding: This research received no external funding.

Acknowledgments: The authors would like to thank all of the athletes and their parents for all of their effort during the study. The authors would also like to thank Dr. Don Morgan for all of his efforts and mentoring.

Conflicts of Interest: The authors declare no conflict of interest.

\section{References}

Abel, T., Platen, P., Rojas Vega, S., Schneider, S., \& Strüder, H. K. (2008). Energy expenditure in ball games for wheelchair users. Spinal Cord, 46(12), 785-790. https://doi-org.elib.uah.edu/10.1038/sc.2008.54

Amsterdam, N. van, Knoppers, A., \& Jongmans, M. (2015). 'It's actually very normal that I'm different'. How physically disabled youth discursively construct and position their body/self. Sport, Education and Society, 20(2), 152-170. https://doi.org/10.1080/13573322.2012.749784

Bernardi, M., Guerra, E., Di Giacinto, B., Di Cesare, A., Castellano, V., \& Bhambhani, Y. (2010). Field evaluation of paralympic athletes in selected sports: implications for training. Medicine and science in sports and exercise, 42(6), 1200-1208. https://doi.org/10.1249/MSS.0b013e3181c67d82

Bloxham, L. A., Bell, G. J., Bhambhani, Y., \& Steadward, R. D. (2001). Time motion analysis and physiological profile of Canadian world cup wheelchair basketball players. Sports Medicine, Training E Rehabilitation, 10(3), 183-198. https://doi.org/10.1080/10578310210398

Bogdanis, G. C., Nevill, M. E., Boobis, L. H., \& Lakomy, H. K. (1996). Contribution of phosphocreatine and aerobic metabolism to energy supply during repeated sprint exercise. Journal of Applied Physiology, 80(3), 876-884. https://doi.org/10.1152/jappl.1996.80.3.876

Bongers, B. C., Rijks, E. B. G., Harsevoort, A. G. J., Takken, T., \& van Brussel, M. (2016). 10m shuttle ride test in youth with osteogenesis imperfecta who use wheelchairs: Feasibility, reproducibility, and physiological responses. Physical Therapy, 96(5), 679-686. https://doi.org/10.2522/ptj.20150082

Brasile, F. M., \& Hedrick, B. N. (1991). A comparison of participation incentives between adult and youth wheelchair basketball players. Palaestra, 7(4), 40-46. https://js.sagamorepub.com/palaestra/issue/view/786

Castelli, D. M., Hillman, C. H., Buck, S. M., \& Erwin, H. E. (2007). Physical fitness and academic achievement in third- and fifth-grade students. Journal of Sport E Exercise Psychology, 29(2), 239-252.

https://doi.org/10.1123/jsep.29.2.239

Coutts, K. D. (1988). Heart rates of participants in wheelchair sports. Paraplegia, 26(1), 43-49. https://doiorg.elib.uah.edu/10.1038/sc.1988.9

Coutts, K. D. (1992). Dynamics of wheelchair basketball. Medicine and Science in Sports and Exercise, 24(2), 231234.

Croft, L., Dybrus, S., Lenton, J., \& Goosey-Tolfrey, V. (2010). A comparison of the physiological demands of wheelchair basketball and wheelchair tennis. International Journal of Sports Physiology and Performance, 5(3), 301-315. https://doi.org/10.1123/ijspp.5.3.301

Crouter, S. E., Clowers, K. G., \& Bassett, D. R. (2006). A novel method for using accelerometer data to predict energy expenditure. Journal of Applied Physiology, 100, 1324-1331. https://doi.org/1152/japplphysiol.00818.2005

Dos Santos, P. P., De Souza, G. C., Leonel Alves, D., Felix Rodacki, A. L., Lima-Silva, A. E., \& De-Oliveira, F. R. (2017). Physiological demands of wheelchair basketball. Journal of Exercise Physiology Online, 20(5), 52-59.

Dunlop, D. D., Song, J., Arnston, E. K., Semanik, P. A., Lee, J., Chang, R. W., \& Hootman, J. M. (2015). Sedentary time in US older adults associated with disability in activities of daily living independent of physical activity. Journal of Physical Activity \& Health, 12(1), 93-101. https://doi.org/10.1123/jpah.2013-0311

Esposito, F., Impellizzeri, F. M., Margonato, V., Vanni, R., Pizzini, G., \& Veicsteinas, A. (2004). Validity of heart rate as an indicator of aerobic demand during soccer activities in amateur soccer players. European Journal of Applied Physiology, 93(1-2), 167-172. https://doi.org/10.1007/s00421-004-1192-4 
Hunter, G. R., Weinsier, R. L., McCarthy, J. P., Enette, D. L.-M., \& Newcomer, B. R. (2001). Hemoglobin, muscle oxidative capacity, and VO2max in African-American and Caucasian women. Medicine and Science in Sports and Exercise, 33(10), 1739-1743. https://doi.org/10.1097/00005768-200110000-00019

Feter, N., Calonego, C., Cavanhi, A.C., \& del Vecchio, F.B. (2018). Wheelchair basketball: fitness and quality of life. European Journal of Adapted Physical Activity, 11(1), 5. https://doi.org/10.5507/euj.2018.001

Iturricastillo, A., Yanci, J., Granados, C., \& Goosey-Tolfrey, V. (2016). Quantifying wheelchair basketball match load: A comparison of heart-rate and perceived-exertion methods. International Journal of Sports Physiology and Performance, 11(4), 508-514. https://doi.org/10.1123/ijspp.2015-0257

Jones, S., \& Drust, B. (2007). Physiological and technical demands of $4 \mathrm{v} 4$ and $8 \mathrm{v} 8$ games in elite youth soccer players. Kinesiology, 39(2), 150-156.

Junior Classification. (n.d.). Retrieved February 1, 2019, from National Wheelchair Basketball Association website: http://www.nwba.org/page/show/3712935-junior-division-classification

Kang, M., Zhu, W., Ragan, B. G., \& Frogley, M. (2007). Exercise barrier severity and perseverance of active youth with physical disabilities. Rehabilitation Psychology, 52(2), 170-176. https://doi.org/10.1037/0090$\underline{5550.52 .2 .170}$

Klavina, A., Ostrovska, K., \& Campa, M. (2017). Fundamental movement skill and physical fitness measures in children with disabilities. European Journal of Adapted Physical Activity, 10(1), 28-37. https://doi.org/10.5507/euj.2017.004

Kraus, L. (2016). 2016 Disability statistics annual report. Rehabilitation Research and Training Center on Disability Statistics and Demographics, 48.

Macfarlane, D.J., Wu, H.L. Inter-unit variability in two ParvoMedics TrueOne 2400 automated metabolic gas analysis systems. European Journal of Applied Physiology, 113(3), 753-762 (2013).

https://doi.org/10.1007/s00421-012-2483-9

Maher, C. A., Williams, M. T., Olds, T., \& Lane, A. E. (2007). Physical and sedentary activity in adolescents with cerebral palsy. Developmental Medicine and Child Neurology, 49(6), 450-457. https://doi.org/10.1111/j.1469-8749.2007.00450.x

Mason, B. S., van der Slikke, R. M. A., Hutchinson, M. J., Berger, M. A. M., \& Goosey-Tolfrey, V. L. (2018). The effect of small-sided game formats on physical and technical performance in wheelchair basketball. International Journal of Sports Physiology and Performance, 1-6, 13(7), 891-896 https://doi.org/10.1123/ijspp.2017-0500

Miles, D. S., Cox, M. H., \& Bomze, J. P. (1989). Cardiovascular responses to upper body exercise in normals and cardiac patients. Medicine and Science in Sports and Exercise, 21(5 Suppl), S126-31.

Miles, D. S., Sawka, M. N., Hanpeter, D. E., Foster, J. E., Doerr, B. M., \& Frey, M. A. (1984). Central hemodynamics during progressive upper- and lower-body exercise and recovery. Journal of Applied Physiology, 57(2), 366-370. https://doi.org/10.1152/jappl.1984.57.2.366

Montgomery, P. G., Pyne, D. B., \& Minahan, C. L. (2010). The physical and physiological demands of basketball training and competition. International Journal of Sports Physiology \& Performance, 5(1), 75-86. https://doi-org.elib.uah.edu/10.1123/ijspp.5.1.75

Moody, J. S., Prochaska, J. J., Sallis, J. F., McKenzie, T. L., Brown, M., \& Conway, T. L. (2004). Viability of parks and recreation centers as sites for youth physical activity promotion. Health Promotion Practice, 5(4), 438443. https://doi.org/10.1177/1524839903258222

Murphy, N. A., Carbone, P. S., \& American Academy of Pediatrics Council on Children with Disabilities. (2008). Promoting the participation of children with disabilities in sports, recreation, and physical activities. Pediatrics, 121(5), 1057-1061. https://doi.org/10.1542/peds.2008-0566

Ortega, F. B., Ruiz, J. R., Castillo, M. J., \& Sjöström, M. (2008). Physical fitness in childhood and adolescence: A powerful marker of health. International Journal of Obesity, 32(1), 1-11. https://doi.org/10.1038/sj.ijo.0803774

Paffenbarger, R. S., Hyde, R., Wing, A. L., \& Hsieh, C. (1986). Physical activity, all-cause mortality, and longevity of college alumni. The New England Journal of Medicine, 314(10), 605-613. http://dx.doi.org.elib.uah.edu/10.1056/NEJM198603063141003

Peltonen, J., \& Tuulari, E. (2018). Polar Team Pro - Portable player tracking system to increase team performance and prevent injuries. 7.

Perez, J., Rabadan, M., Pacheco, J., \& Sampedro, J. (2007). Does heart rate correlate velocity during wheelchair basketball competition? Some reflections in relation to functional classification. Sport for Persons with a Disability Perspectives, 7, 151-174. https://doi.org/10.3233/978-1-60750-080-3-412

Piovezana, P., Souza, G., Alves, D., Rodacki, F., Lima-Silva, A., \& Roberto De-Oliveira, F. (2017). Physiological demands of wheelchair basketball. Journal of Exercise Physiology Online, 20, 52-59. 
Piercy, K. L., Troiano, R. P., Ballard, R. M., Carlson, S. A., Fulton, J. E., Galuska, D. A., George, S.M., \& Olson, R.D. (2018). The physical activity guidelines for Americans. JAMA, 320(19), 2020-2028. https://doi.org/10.1001/jama.2018.14854

Rhodes, J.M., Mason, B.S., Perrat, B., Smith, M.J., \& Goosey-Tolfrey, V.L. (2014). The validity and reliability of a novel indoor player tracking system for use within wheelchair court sports. Journal of Sports Sciences, 32(17), 1639-1647. https://doi.org/10.1080/02640414.2014.910608

Rhodes, J. M., Mason, B. S., Perrat, B., Smith, M. J., Malone, L. A., \& Goosey-Tolfrey, V. L. (2015). Activity profiles of elite wheelchair rugby players during competition. International Journal of Sports Physiology and Performance, 10(3), 318-324. https://doi.org/10.1123/ijspp.2014-0203

Rimmer, J. A., \& Rowland, J. L. (2008). Physical activity for youth with disabilities: A critical need in an underserved population. Developmental Neurorehabilitation, 11(2), 141-148. https://doi.org/10.1080/17518420701688649

Rimmer, J. H., Riley, B., Wang, E., Rauworth, A., \& Jurkowski, J. (2004). Physical activity participation among persons with disabilities: Barriers and facilitators. American Journal of Preventive Medicine, 26(5), 419-425. https://doi.org/10.1016/j.amepre.2004.02.002

Rowland, J. L., \& Rimmer, J. H. (2012). Feasibility of using active video gaming as a means for increasing energy expenditure in three nonambulatory young adults with disabilities. PM $\mathcal{E}$ R: The Journal of Injury, Function, and Rehabilitation, 4(8), 569-573. https://doi.org/10.1016/j.pmrj.2012.03.011

Roy, J. L. P., Menear, K. S., Schmid, M. M. A., Hunter, G. R., \& Malone, L. A. (2006). Physiological responses of skilled players during a competitive wheelchair tennis match. Journal of Strength and Conditioning Research, 20(3), 665-671. https://doi.org/10.1519/r-17845.1

Sawka, M. N., Miles, D. S., Petrofsky, J. S., Wilde, S. W., \& Glaser, R. M. (1982). Ventilation and acid-base equilibrium for upper body and lower body exercise. Aviation, Space, and Environmental Medicine, 53(4), 354-359.

Schmid, A., Huonker, M., Stober, P., Barturen, J. M., Schmidt-Trucksäss, A., Dürr, H., ...\& Keul, J. (1998). Physical performance and cardiovascular and metabolic adaptation of elite female wheelchair basketball players in wheelchair ergometry and in competition. American Journal of Physical Medicine E Rehabilitation, 77(6), 527-533. https://doi-org.elib.uah.edu/10.1097/00002060-199811000-00015

Sporner, M. L., Grindle, G. G., Kelleher, A., Teodorski, E. E., Cooper, R., \& Cooper, R. A. (2009). Quantification of activity during wheelchair basketball and rugby at the National Veterans Wheelchair Games: A pilot study. Prosthetics and Orthotics International, 33(3), 210-217. https://doi.org/10.1080/03093640903051816

Tordi, N., Dugue, B., Klupzinski, D., Rasseneur, L., Rouillon, J. D., \& Lonsdorfer, J. (2001). Interval training program on a wheelchair ergometer for paraplegic subjects. Spinal Cord, 39(10), 532-537. https://doi.org/10.1038/sj.sc.3101206

Temple, V.A., Alston, K.F., Elder, J.J., \& Stuart-Hill, L. (2019). The effect of a pacer versus no-pacer on submaximal fitness test results among Special Olympics athletes. European Journal of Adapted Physical Activity, 12(1), 5.

U.S. Census Bureau QuickFacts: United States. (2016). Retrieved May 29, 2018, from https://www.census.gov/quickfacts/fact/table/US/PST045216

U.S. Census Bureau QuickFacts: United States. (2018). Retrieved October 4, 2019, from https://www.census.gov/quickfacts/fact/table/US/PST045218

Yanci, J., Iturricastillo, A., \& Granados, C. (2014). Heart rate and body temperature response of wheelchair basketball players in small-sided games. International Journal of Performance Analysis in Sport, 14(2), 535544. https://doi.org/10.1080/24748668.2014.11868741

Ziv, G., \& Lidor, R. (2009). Physical attributes, physiological characteristics, on-court performances and nutritional strategies of female and male basketball players. Sports Medicine, 39(7), 547-568. https://doiorg.elib.uah.edu/10.2165/00007256-200939070-00003

(C) 2020 by the authors. Submitted for possible open access publication under the terms and conditions of the Creative Commons Attribution (CC BY) license (http://creativecommons.org/licenses/by/4.0/). 